Bull. Fac. Agric., Cairo Univ., 63:252-260 (2012)

\title{
USING TREND ANALYSIS MODELS TO IMPROVE EFFICIENCY OF WHEAT Triticum aestivum L. VARIETY TRIALS.
}

(Received:9.4.2012)

\author{
By \\ M. A. Hager \\ Agronomy Department, Faculty of Agriculture, Al-Azhar University, Cairo, Egypt.
}

\begin{abstract}
Spatial variability is a common problem. It perhaps faces the agronomists and plant breeders in variety trials especially with large number of genotypes. Although, the blocking system using complete or incomplete block designs accounted for a proportion of this local heterogeneity as inter-block variability, a considerable amount of intra-block variability still remains unaccounted for and this may lead to mask the differences between genotype means. To hold this undesirable part of variability, yield data from 29 genotypes of wheat and one released cultivar (Giza 168) were analyzed in a variety trial using randomized complete block design $(\mathrm{RCBD})$, simple rectangular lattice $(5 \times 6)$ and trend analysis. The field experiments were carried out at the experimental farm of Agronomy Department, Faculty of Agriculture, Al-Azhar University during 2009/2010 and 2010/2011 growing seasons. The coefficient of determination $\left(\mathrm{R}^{2}\right)$ of the model, Relative Efficiency (RE\%), Type I error and Type II error were used as statistical criteria to investigate the usefulness of trend analysis over RCBD and lattice design model in accounting for spatial variability. Also, Pearson and Spearman rank correlation coefficients were computed to identify the effect of the used models on the ranks of the genotype means. The obtained estimates showed the superiority of trend analysis over RCBD in both seasons, Type I error and Type II error plus high values of $\mathrm{R}^{2} \%$ of the model and RE\%. Similar performance of the models of lattice design and trend analysis were true in both seasons. Highly significant correlation coefficients (Pearson and Spearman) were detected indicating considerable degree of similarity between the tested models for adjusting the genotype means for spatial variability. Finally, it could be concluded that trend analysis appeared to be a useful procedure to account for intra-block heterogeneity especially when the pattern of this variation is complex and in curvilinear form.
\end{abstract}

Key words : spatial variability, spearman rank correlation, type II error, wheat.

\section{INTRODUCTION}

In Egypt, wheat (Triticum aestivum, L.) has been considered to be the first strategic cereal crop,mainly for human and partially for animal feeding. The total annual consumption of wheat is about 12.0 million tons, while corresponding production in 2010/2011 season was about 8.2 million tons. Therefore, there is a gab between the national need and the local wheat production. Narrowing the gap between production and consumption is the most important target. Nevertheless, in Egypt, wheat could not occupy its appropriate place and also it is not popular enough among farmers. This is mainly due to lack of a proper marketing system, fluctuating market prices and the high wheat competition among the main winter crops, e.g. berseem and sugar beet.
Using high yielding wheat genotypes is one of the objectives to overcome its constraints. But the accurate estimates of genotype or variety differences require controlling error variation either by the use of appropriate experimental design or by effective statistical analysis. The randomized complete block design (RCBD), because of its simplicity, is still one of the first choices for conducting variety trials. The efficiency of RCBD analysis depends on whether or not plots within each block are relatively homogenous. However, intra-site variability within blocks of more than 8 to 12 plots often occurs in field trials (Stroup et al.,1994). Thus, efficiency of RCBD is often poor in variety trials involving large number of entries. In this case, an 
incomplete block design such as lattice structure, that has small blocks, may be the alternative choice of RCBD. But the use of lattice designs may be limited because the spatial variability also may be found through small blocks, in addition to some difficult computations of lattice analysis.

Recently, numerous methods of analysis have been proposed to remove spatial variability and thereby improve precision of genotype comparison. Trend analysis (Kirk et al., 1980) is one of these methods that exploit the information on plot positions to estimate and correct intra-site variability within and among blocks.

Many investigators discussed the adequacy of trend analysis models to reduce error mean square compared to RCBD and lattice designs (e.g., Kirk et al., 1980, Tamura et al., 1988, Bowman, 1990; Browine et al. , 1993; as well as Nasr and El-Hady 1999). They found that trend analysis was more efficient than using RCBD and at least is equivalent to lattice analysis.

Despite the recent interest shown in corrective models of spatial variability such as trend analysis, the model is rarely used in yield trials in Egypt. Our purpose in this research was to compare trend analysis with RCBD and lattice analyses to determine the usefulness of trend analysis in identifying superior genotypes in wheat breeding programs.

\section{MATERIALS AND METHODS}

The present investigation was carried out at the experimental farm of the Agronomy Department, Faculty of Agriculture, Al-Azhar University, during 2009/2010 and 2010/2011 growing seasons, to evaluate the yielding ability of 30 genotypes of wheat. One of them is a released cultivar namely, Giza 168.

\subsection{Genotypic materials.}

The evaluated 29 genotypes were as the following: 23 regenerated somaclones [15 from Sakha 8 (S8), 3 from Lerma Rojo 64 (LR) and 5 Sakha 69 (S69)] . In additions, 7 genotypes (the initial genotypes were used as checks, viz the four Egyptian wheat cultivars Sakha 8, Sakha 69 and Giza 157, Giza 160. Moreover, two exotic ones $v i z$ the Spanish cultivar Lerma Rojo 64 and the Mexican cultivar Tobari 66 . These genotypes are presented in Table (1). It might be mentioned that the somaclone used were in the $9^{\text {th }}$ and $10^{\text {th }}$ regenerations from an experiment of tissue culture technique.

Wheat genotypes were randomly disributed in a simple rectangular lattice design $(5 \times 6)$ according to Cochran and Cox (1957). The field layout consisted of grid of 12 rows and 5 columns, where the replications were arranged in vertical line in both seasons (Fig. 1).

The plot area was $3 \mathrm{~m}^{2}$ including four rows, $3 \mathrm{~m}$ long and $0.25 \mathrm{~m}$ apart. All agricultural practices were maintained at the recommended levels to satisfy maximum yield.

\subsection{Statistical analysis}

Data of grain yield (ardab/fed) were firstly analyzed using the traditional models of RCBD and simple rectangular lattice $(5 \times 6)$ according to Cochran and Cox (1957). Then, the data were reanalyzed using trend analysis.

In trend analysis, plot position would be identified by row and column number to form a grid of plots. The method assumed that the soil heterogeneity could be represented by polynomial regression equation on the grid of plots using row and column numbers as independent variables in an analysis of multiple covariance. The resulting function has come to be known as a "response surface model".

Table (1): Names of the tested wheat genotypes.

\begin{tabular}{|c|c|c|c|}
\hline No. & Genotype & No. & Genotype \\
\hline 1 & Sakha 8 (S8) & 16 & S8/17 \\
\hline 2 & $\mathrm{~S} 8 / 2$ & 17 & $\mathrm{~S} 8 / 18$ \\
\hline 3 & $S 8 / 3$ & 18 & $\mathrm{~S} 8 / 19$ \\
\hline 4 & $\mathrm{~S} 8 / 4$ & 19 & Tobari 66 (T66) \\
\hline 5 & $\mathrm{~S} 8 / 5$ & 20 & $S 8 / 21$ \\
\hline 6 & $\mathrm{~S} 8 / 6$ & 21 & Sakha 69 (S69) \\
\hline 7 & $\mathrm{~S} 8 / 7$ & 22 & S69/1 \\
\hline 8 & $\mathrm{LR} / 1$ & 23 & S69/2 \\
\hline 9 & S8/9 & 24 & $\mathrm{~S} 69 / 3$ \\
\hline 10 & $\mathrm{~S} 8 / 10$ & 25 & S69/4 \\
\hline 11 & $\mathrm{~S} 8 / 11$ & 26 & S69/5 \\
\hline 12 & $\mathrm{~S} 8 / 13$ & 27 & Giza 157 (G157) \\
\hline 13 & S8/14 & 28 & $\mathrm{LR} / 2$ \\
\hline 14 & $\mathrm{LR} / 3$ & 29 & Lerma Rojo 64 (LR) \\
\hline 15 & G160 (G160) & 30 & Giza168 \\
\hline
\end{tabular}

Accordingly, if row position indexed by $\mathrm{R}_{\mathrm{i}}$ and column position indexed by $\mathrm{C}_{\mathrm{j}}$ in a rectangular 


\begin{tabular}{|c|c|c|c|c|c|c|}
\hline \multirow{2}{*}{ Rep. } & \multirow{2}{*}{$\begin{array}{c}\text { Row } \\
\text { no. }\end{array}$} & \multicolumn{5}{|c|}{ Columns } \\
\hline & & 1 & 2 & 3 & 4 & 5 \\
\hline \multirow{6}{*}{ (1) } & 1 & 1 & 2 & 3 & 4 & 5 \\
\hline & 2 & 6 & 7 & 8 & 9 & 10 \\
\hline & 3 & 11 & 12 & 13 & 14 & 15 \\
\hline & 4 & 16 & 17 & 18 & 19 & 20 \\
\hline & 5 & 21 & 22 & 23 & 24 & 25 \\
\hline & 6 & 26 & 27 & 28 & 29 & 30 \\
\hline \multirow{6}{*}{ (2) } & 7 & 6 & 11 & 16 & 21 & 26 \\
\hline & 8 & 1 & 12 & 17 & 22 & 27 \\
\hline & 9 & 2 & 7 & 18 & 23 & 28 \\
\hline & 10 & 3 & 8 & 13 & 24 & 29 \\
\hline & 11 & 4 & 9 & 14 & 19 & 30 \\
\hline & 12 & 5 & 10 & 15 & 20 & 25 \\
\hline
\end{tabular}

Fig. (1): Field layout showing random allocation of the 30 genotypes over arrayed in grid of 12 rows $\times 5$ columns. The design is a simple rectangular lattice $(5 \times 6)$.

$\mathrm{RxC}$ layout of plots (field layout), then the model of response surface as outlined by Kirk et al. (1980) would be as follows:

$$
\begin{aligned}
& Y_{i(j k)}=\mu+T_{i}+ \\
& \sum_{x=1}^{g} \beta_{x y} R_{j}^{x}+\sum_{z=1}^{h} \beta_{y z} C_{k}^{z}+\sum_{x=1}^{g} \sum_{z=1}^{h} \beta_{x z} R_{j}^{x} C_{k}^{z}+E_{i(j k)}
\end{aligned}
$$

Where:

$Y_{i(j k)}=$ Observation of the $\mathrm{i}^{\text {th }}$ treatment, located on the $\mathrm{j}^{\text {th }}$ row and $\mathrm{k}^{\text {th }}$ column.

$\mu=$ Grand mean.

$T_{i}=$ Effect of the $\mathrm{i}^{\text {th }}$ treatment.

$\sum_{x=1}^{g} \beta_{x y} R_{j}^{x}=$ Polynomial regression effect of the $\mathrm{j}^{\text {th }}$ row coordinate.

$\sum_{z=1}^{h} \beta_{y z} C_{k}^{z}=$ Polynomial regression effect of the $\mathrm{k}^{\text {th }}$ column coordinate.

$\sum_{x=1}^{g} \sum_{z=1}^{h} \beta_{x z} \boldsymbol{R}_{j}^{x} C_{k}^{z}=$ Polynomial regression effect of the interaction between the $\mathrm{j}^{\text {th }}$ row and $\mathrm{k}^{\text {th }}$ column coordinate, and

$E_{i(j k)}=$ Random error associated with the response.
Kirk et al.(1980) explained that fitting the polynomial response surface aims at holding the systematic component of soil heterogeneity (among rows and/or columns), and the estimates of precision are based only on the remaining random component of the error term.

Although, trend analysis can increase efficiency, potential shortcomings of this approach should not be overlooked. This include problems associated with overfitting or with using an incorrect response surface model. Overfitting occurs if the true function of the soil heterogeneity is a polynomial but we fit a polynomial with too many terms. Fitting an incorrect model occurs if too few terms are fitted, or if the true function cannot be modeled as a polynomial. The problems of overffiting or fitting an incorrect model of soil heterogeneity can cause confounding between polynomial term and genotype effects which will lead to biased estimates of genotype effects and an upwardly biased estimate of error term. So, an important component of trend analysis is deciding how to select the right polynomial function of plot to plot variation. In this study, a maximum of significant eight terms was permitted to reflect the systematic variation component of error (Bowman, 1990).

The comparison among the used models of analysis was assessed on the basis of:

1- The relative efficiency (RE \%) to assess the improvement in precision of trend analysis over RCBD and lattice models. In the current study, the RE\% is computed as the ratio between mean square of error (MSE) of RCBD and those from the two models of analysis (lattice and trend). Since, error degrees of freedom for the used models of analysis more than 20, their effects on RE\% were negligible (Bowman, 1990).

2- P-value of genotype source of variation was recorded to express Type I error.

3- Type II error was estimated for genotype source of variation to investigate the ability of the model to detect the significant differences among genotype means (Kirk, 1995).

In fact, the researchers in Egypt could not determine Type II error of field experiments. They based their management decisions only on a Pvalue (Type I error). Glaz and Dean (1988) mentioned that, if Type II error has been committed, it would be more harmful than Type I error (P- value). Also, Kirk (1995) recommended 
that Type II error must be less than 0.2 for statistically acceptable precision.

Estimates of adjusted genotype means and their ranks were compared using Pearson and Spearman rank correlations to identify the effect of these methodologies on the detection of elite genotypes.

Also, the valid standard error was used to estimate least significant difference (LSD) between pair-wise genotype means.

Minitab statistical software was used to automate somewhat difficult computations required for lattice and trend analyses. General Linear Model (GLM) option was used to run these models.

\section{RESULTS AND DISCUSSION}

The analysis of variance for grain yield (ardab/fed) using RCBD, simple rectangular lattice $(5 \times 6)$ and trend analysis during 2009/ 2010 and 2010/ 2011 seasons is presented in Table (2). The results show that fitting RCBD model, genotypes as source of variation was insignificant in both seasons.

These results supported the fact that unknown variation did extend through the experimental fields (Kirk et al. 1980). Warren and Mendez (1982), indicating that block failed to account for intra-site heterogeneity when they are too large, poorly oriented, or have within block heterogeneity.

Lattice analysis recorded significant F-test $(\mathrm{P}<$ $0.05)$ for genotype effect in both seasons. The significance of adjusted genotype effect may be due to the large reduction (almost $32.45 \%$ ) of the MSE from 18.49 for RCBD to 12.49 using lattice analysis. Also, in 2009/2010 season, the significance of adjusted block term $(\mathrm{P}<0.05)$ indicated that a considerable component of spatial variability may be found within the relatively large replication of RCBD (consisting of 30 plots each). The use of small block structure of lattice design (consisting of only 5 plots each), effectively removed the spatial variation in part.

The suitability of lattice design for experiments with large number of treatments was reported by Cochran and Cox (1957).

The previous results forced the need for using other corrective analysis such as trend analysis, which may improve the precision of the analysis. In fact, statistically proper results were obtained using trend analysis, as recorded significant differences $(\mathrm{P}<0.05)$ due to genotypes in both seasons.

The effectiveness of trend analysis proves that the plot to plot variation was in form that could be adequately fitted by the supposed response surface model. Already, the highly significance of trend term in both seasons confirms the previous remark and indicates that this technique is a good reliable way to reflect the local fertility (Browine et al., 1993).

One advantage arises from trend analysis over lattice model; is that trend analysis requires only few degrees of freedom (df) for controlling the local variability (4 and $6 \mathrm{df}$ for trend source of variation in 2009 and 2010 seasons, respectively), while the lattice analysis needed $11 \mathrm{df}$ to control local variability through the trial ( $1 \mathrm{df}$ for replication and $10 \mathrm{df}$ for blocks).

Accordingly, it could be concluded that a model which depends on positional information about the field plots, such as trend analysis, may be an effective tool to discover and overcome the spatial heterogeneity through the experimental fields, especially when the RCBD is ineffective. The present results are in agreement with Pearce (1978); Lin et al. (1993); Kempton et al. (1994) and Qiao et al. (2000).

In order to verify a right decision about the statistically preferred model, it should discuss the results in Table (3) which showed the comparison between the tested models using different statistical criteria. The comparison was carried out using $\mathrm{R}^{2} \%$, RE \%, Type I and Type II errors. The model is statistically preferred when it exhibited highest values of the $\mathrm{R}^{2} \%$ and $\mathrm{RE} \%$ plus acceptable values of Type 1 error and Type II error.

Results in Table (3), showed disappointing results using RCBD in both seasons. The model showed lack of fit measured by $\mathrm{R}^{2} \%$ values being 66 and 65 for 2009/2010 and 2010/2011 seasons, respectively.

High values of Type I error and Type $\Pi$ error were recorded 0.05 and 0.09 , respectively. Using RCBD model in 2009/2010 season compared to 0.70 and 0.10 in the second season. It is easy to note that RCBD model was very close to detect significant differences between genotype means in the second season. The current results confirmed that the spatial heterogeneity in the field trials is a real despite of the use of replication and randomization by RCBD.

In any experiment, damage from outside causes or conditions can lead to intra-site variability which is not related to the replication and therefore, can not be controlled by them even they were in the appropriate direction (Pearce, 
Table (2): Analyses of variance for grain yield (Ardab/fed) using RCBD, simple rectangular lattice $(5 \times 6)$ and trend analysis models during $2009 / 2010$ and $2010 / 2011$ seasons.

\begin{tabular}{|c|c|c|c|c|c|c|c|}
\hline \multirow{2}{*}{$\begin{array}{l}\text { Models of } \\
\text { analysis }\end{array}$} & \multirow{2}{*}{ Source of variation } & \multicolumn{3}{|c|}{ Season $2009 / 2010$} & \multicolumn{3}{|c|}{ Season 2010/2011 } \\
\hline & & D. F. & S. S. & M. S. & D. F. & S. S. & M. S. \\
\hline \multirow{3}{*}{ RCBD } & Replication & 1 & 25.68 & 25.68 & 1 & 10.46 & 10.46 \\
\hline & Genotype & 29 & 1001.04 & 34.52 & 29 & 1027.72 & 35.44 \\
\hline & Error & 29 & 536.16 & 18.49 & 29 & 564.84 & 19.48 \\
\hline \multirow{6}{*}{$\begin{array}{c}\text { Simple } \\
\text { rectangular } \\
\text { lattice }(5 \times 6)\end{array}$} & Replication & 1 & 25.68 & 25.68 & $\mathbf{1}$ & 10.46 & 10.46 \\
\hline & Block/Rep. (adj.) & 10 & 298.91 & 29.89 & 10 & 357.30 & $35.73 *$ \\
\hline & Genotype (unadj.) & 29 & 1001.04 & $34.52 *$ & 29 & 1027.72 & $35.44 * *$ \\
\hline & Block/Rep. (unadj.) & 10 & 191.15 & 19.11 & 10 & 250.37 & 25.03 \\
\hline & Genotype (adj.) & 29 & 1108.80 & $38.23 * *$ & 29 & 1134.65 & $39.13 * *$ \\
\hline & Intrablock error & 19 & 237.24 & 12.49 & 19 & 207.54 & 10.92 \\
\hline \multirow{4}{*}{$\begin{array}{c}\text { Trend } \\
\text { analysis }\end{array}$} & Trend & 4 & 122.00 & 30.50 & 6 & 120.70 & 20.12 \\
\hline & Genotype & 29 & 1092.53 & $37.67 * *$ & 29 & 1206.61 & $41.61 * *$ \\
\hline & Error & 26 & 348.36 & 13.40 & 24 & 275.72 & 11.49 \\
\hline & Total & 59 & 1562.87 & & 59 & 1603.02 & \\
\hline
\end{tabular}

* and **: Significant at 0.05 and 0.01 probability levels, respectively.

Table (3): Estimates of $\mathbf{R}^{2} \%$, RE \%, Type I and Type II errors for RCBD, simple rectangular lattice $(5 \times 6)$ and trend analysis models in $2009 / 2010$ and $2010 / 2011$ seasons.

\begin{tabular}{|l||c|c|c||c|c|c|}
\hline \multirow{2}{*}{ Preference criteria } & \multicolumn{3}{c||}{ 2009/2010 season } & \multicolumn{3}{c|}{$2010 / 2011$ season } \\
\cline { 2 - 7 } & RCBD & Lattice & Trend & RCBD & Lattice & Trend \\
\hline $\mathbf{R}^{2} \%$ & $\mathbf{6 6}$ & $\mathbf{7 6}$ & $\mathbf{7 8}$ & $\mathbf{6 5}$ & $\mathbf{8 2}$ & 83 \\
\hline RE \% & 100 & 148 & 138 & 100 & 178 & 170 \\
\hline Type I error & $\mathbf{0 . 0 5}$ & $\mathbf{0 . 0 0 7}$ & $\mathbf{0 . 0 0 5}$ & $\mathbf{0 . 7 0}$ & $\mathbf{0 . 0 0 3}$ & $\mathbf{0 . 0 0 1}$ \\
\hline Type II error & $\mathbf{0 . 0 9}$ & $\mathbf{0 . 0 5}$ & $\mathbf{0 . 0 2}$ & $\mathbf{0 . 1 0}$ & $\mathbf{0 . 0 1}$ & $\mathbf{0}$ \\
\hline
\end{tabular}

1980). Also, Lin et al. (1993) mentioned that the lack of the choice of a proper orientation of replication layout is one of the factors that limit the successful use of RCBD.

Promising results were observed using lattice analysis in 2009/2010 and 2010/2011 seasons. The model secured goodness of fit by value of $\mathrm{R}^{2}$ being 76 and 82 respectively, in addition to a gain in efficiency over RCBD recording 48 and 78 respectively. Also, there was clear improvement for detecting differences among genotype means since $\mathrm{P}$ value dropped from 0.05 for RCBD to 0.007 and from 0.70 RCBD to 0.003 with lattice analysis. Acceptable value of Type II error was also recorded (0.05) and (0.01) using lattice analysis. The current results indicated that the small blocks of lattice structure were more homogenous compared to large area of the complete replication.

Regarding trend analysis, it exhibited considerably greater precision compared to RCBD in both seasons. Somewhat goodness of fit was satisfied using trend model with $\mathrm{R}^{2}$ value of 78 and 83 in 2009/2010 and 2010/2011, respectively. Cleary, there was noticeable gain in efficiency of trend analysis over RCBD with values of 38 and 70 in both seasons, respectively.

Undoubtedly, the current measures are considered good results under agricultural field conditions. Lower values of Type I error 
Table (4): Estimated grain yield (ardab/fed) of wheat genotype means for the used models of analysis in 2009/2010 and 2010/2011 seasons.

\begin{tabular}{|c|c|c|c|c|c|c|c|}
\hline \multirow{2}{*}{ No. } & \multirow{2}{*}{ Genotype } & \multicolumn{3}{|c|}{$2009 / 2010$} & \multicolumn{3}{|c|}{$2010 / 2011$} \\
\hline & & RCBD & Lattice & Trend & RCBD & Lattice & Trend \\
\hline 1 & Sakha 8 & $22.02(4)$ & 23.69 (2) & $24.32(2)$ & 20.81 & 22.74 & 23.92 \\
\hline 2 & $\mathrm{~S} 8 / 2$ & 12.77 & 15.18 & 13.84 & 20.69 & $24.19(5)$ & $23.95(6)$ \\
\hline 3 & S8/3 & $22.52(3)$ & $22.22(4)$ & $22.27(4)$ & 18.40 & 20.79 & 21.67 \\
\hline 4 & $\mathrm{~S} 8 / 4$ & $21.45(5)$ & 20.65 & $20.44(6)$ & $21.57(6)$ & $24.89(4)$ & $24.45(4)$ \\
\hline 5 & S8/5 & 12.35 & 12.70 & 12.10 & 10.82 & 10.98 & 11.16 \\
\hline 6 & S8/6 & $23.62(2)$ & $24.30(1)$ & $24.57(1)$ & 15.76 & 19.39 & 18.20 \\
\hline 7 & S8/7 & $23.86(1)$ & $22.81(3)$ & $22.88(3)$ & 18.60 & 21.60 & 21.69 \\
\hline 8 & $\mathrm{LR} / 1$ & 10.91 & 7.15 & 8.60 & 15.09 & 16.98 & 18.18 \\
\hline 9 & S8/9 & 15.66 & 11.39 & 12.60 & $23.80(4)$ & $26.62(3)$ & $26.50(2)$ \\
\hline 10 & S8/10 & 12.90 & 9.78 & 10.59 & $24.27(3)$ & $23.93(6)$ & $24.43(5)$ \\
\hline 11 & S8/11 & $18.74(6)$ & 20.94 & 19.63 & 15.78 & 18.28 & 15.78 \\
\hline 12 & S8/13 & 16.70 & 16.43 & 16.90 & $21.97(5)$ & 22.26 & 22.45 \\
\hline 13 & S8/14 & 10.09 & 7.85 & 7.72 & $26.15(1)$ & $26.91(2)$ & $26.81(1)$ \\
\hline 14 & LR/3 & 11.97 & 9.23 & 8.85 & $25.42(2)$ & $27.10(1)$ & $25.67(3)$ \\
\hline 15 & G160 & 13.96 & 12.37 & 11.60 & 14.75 & 13.27 & 12.47 \\
\hline 16 & S8/17 & 16.80 & 19.23 & 18.61 & 13.01 & 13.35 & 11.36 \\
\hline 17 & S8/18 & 12.43 & 12.40 & 13.55 & 12.89 & 11.01 & 11.72 \\
\hline 18 & S8/19 & 12.22 & 12.92 & 12.10 & 17.83 & 17.54 & 16.82 \\
\hline 19 & Tobari 66 & 12.62 & 10.10 & 10.41 & 13.97 & 13.49 & 12.56 \\
\hline 20 & $\mathrm{~S} 8 / 21$ & 13.44 & 12.08 & 11.99 & 14.65 & 11.01 & 10.71 \\
\hline 21 & Sakha 69 & 15.80 & $21.17(6)$ & 18.69 & 17.69 & 16.57 & 15.79 \\
\hline 22 & S69/1 & 18.62 & $21.53(5)$ & $20.82(5)$ & 20.97 & 17.63 & 19.55 \\
\hline 23 & S69/2 & 14.88 & 18.54 & 15.85 & 20.17 & 18.41 & 18.92 \\
\hline 24 & S69/3 & 12.70 & 13.64 & 12.33 & 17.38 & 14.51 & 16.13 \\
\hline 25 & S69/4 & 15.10 & 16.69 & 14.74 & 11.41 & 6.31 & 7.22 \\
\hline 26 & S69/5 & 12.30 & 14.84 & 15.90 & 12.14 & 12.05 & 10.89 \\
\hline 27 & Giza 157 & 9.43 & 9.51 & 12.34 & 14.73 & 12.42 & 13.96 \\
\hline 28 & $\mathrm{LR} / 2$ & 9.35 & 10.17 & 11.03 & 16.13 & 15.40 & 15.52 \\
\hline 29 & Lerma & 14.66 & 12.76 & 15.01 & 18.67 & 16.83 & 18.07 \\
\hline 30 & Giza168 & 16.22 & 13.82 & 15.81 & 20.81 & 13.49 & 13.40 \\
\hline \multicolumn{2}{|c|}{ LSD at 0.05} & NS & 8.66 & 8.07 & NS & 8.10 & 7.63 \\
\hline
\end{tabular}

Bold, italic and underline cells refer to the highest yielding 6 genotypes and their ranks.

Table (5): Pearson (above diagonal) and Spearman (below diagonal) correlation coefficients between wheat genotype means for the used models of analysis during 2009/2010 and 2010/2011 seasons.

\begin{tabular}{|l|r|r|r||r|r|r|}
\hline \multirow{2}{*}{$\begin{array}{l}\text { Models of } \\
\text { analysis }\end{array}$} & \multicolumn{2}{|c|}{$\mathbf{2 0 0 9 / 2 0 1 0}$} & \multicolumn{2}{|c|}{$\mathbf{2 0 1 0 / 2 0 1 1}$} \\
\cline { 2 - 7 } RCBD & RCBD & Lattice & \multicolumn{1}{|c|}{ Trend } & RCBD & \multicolumn{1}{c|}{ Lattice } & \multicolumn{1}{c|}{ Trend } \\
\hline Lattice & 1 & $0.89 * *$ & $0.92 * *$ & 1 & $0.88 * *$ & $0.90 * *$ \\
\hline Trend & $0.86^{* *}$ & 1 & $0.97 * *$ & $0.88^{* *}$ & 1 & $0.98 * *$ \\
\hline
\end{tabular}

**: Significant at 0.01 probability level of analysis. 
and Type $\Pi$ error were obtained in both seasons indicating high ability of trend analysis to detect the significant difference between genotype means.

Other striking feature of trend analysis was that it accounted for the plot to plot variation across two dimensions of the field map while RCBD and lattice models concerned only with one direction. So, under the conditions of the current trial, the trend analysis is statistically recommended over RCBD and lattice analysis model.

The present results are coincided with those obtained by several investigators in their studies on wheat and other crops. These results are in agreement with Kirk et al. (1980); Pearce, (1980); Tamura et al. (1988), Bowman, (1990); Browine et al. (1993); Nasr, (1994); Nasr and El-Hady (1999); Stroup et al. (1994)and Fares et al .(2011). They found that trend analysis should be used as ancillary device along with RCBD and must be invoked especially when RCBD could not remove the unwanted variation to large extent from the field data.

The genotype means of grain yield (ardab/fed) using the three models of analysis were estimated for both seasons shown in Table (4). Also, Table (4) contained the ranks of the 6 highest yielding genotypes resulted from the statistically preferred model (trend analysis) considering selection intensity of $20 \%$ of the most productive genotypes (6 in 30 genotypes in the current study).

In 2009/2010 season, genotypes S8/6, Sakha 8, $\mathrm{S} 8 / 7, \mathrm{~S} 8 / 3, \mathrm{~S} 69 / 1$ and S8/4 produced the highest seed yield recording 24.57, 24.32, 22.88, 22.27, 20.82 and 20.44 (ardab/fed), respectively.

In the second season, genotype $\mathrm{S} 8 / 14$, gave the highest grain yield followed by S8/9, LR/3, S8/4, S8/10 and S8/2 recording 26.81, 26.50, 25.67, 24.45, 24.43 and 23.95 (ardab/fed), respectively.

The differences between the ranks of the best genotypes through both seasons may be attributed to the effect of environmental factors and their interactions with genotypes. According to the previous results, these genotypes are promising and should be taken in consideration by wheat breeders. These results are in accordance with Abdelkareem and Ahmed (2003).

To know the degree of similarity of the mean performance of genotypes using the three used models, Pearson and Spearman rank correlation coefficients were computed between the genotype means resulted from tested models in both seasons Table (5). Highly significant relation $(\mathrm{P}<0.01)$ was observed with all coefficients of correlation (Pearson and Spearman) in both seasons. The values of correlation coefficients ranged from 0.86 to 0.90 overall two types of correlation.

The results cleared considerable degree of similarity between the used models for adjusting the genotype means for spatial variability, irrespective of, the different scientific backgrounds of the three tested models. The current conclusions were in harmony with those reported by Browine et al (1993) and Stroup et al (1994), who mentioned that using different methods to remove intra-site variation can improve precision, but choosing the most appropriate analysis may be hard.

Finally, the present study gives the following conclusions:

\section{Conclusions}

- The plot to plot variation in the field trials is present despite of the use of blocking and randomization by the classical experimental designs.

- In any field experiment, damage from outside causes or conditions can lead to intra-site heterogeneity which is unrelated to the replication and therefore, can not be controlled by them even when they are in the appropriate orientation.

- When the spatial variability within replication is very small, then the classical design would be satisfactory to verify a considerable level of precision and using the trend analysis in this case would confirm the results.

- When the intra-site variability in the field trials is in the form of a very complex structure, then using trend analysis is essential and provides a valuable addition as data a analysis tool.

\section{Acknowledgement}

Foremost, I would like to express my sincere gratitude to prof. KASEM ZAKI AHMED; Faculty of Agriculture, Minia University and prof. SAMY AFIAH; Desert Research Center, AlMatarya, Cairo, Egypt for providing the genotypes of this research.

\section{REFERENCES}

Abdelkareem A. A. and Ahmed K. Z. (2003). Somaclonal variation in bread wheat (Triticum aestivum L.). 2. Comparative field performance of somaclones and their original cultivars. Egypt. J. Plant Breed., 7: 457-469.

Bowman D.T. (1990). Trend analysis to improve efficiency of agronomic trials in Flue - Cured Tobacco. Agron. J., 82: 499-501. 
Browine C., Bowman D.T. and Burton J.W. (1993). Estimating spatial variation in analysis of data from yield trials: a comparison of methods. Agron. J., 85: 1244-1253.

Cochran W.G. and Cox G.M. (1957). Experimental Designs. $2^{\text {nd }}$ ed. John Wiley \& Sons, New York, USA.

Fares W. M., Fateh H.S.A. and Morsy A.R. (2011). Improving the precision of soybean variety trials using trend analysis models. Egypt. J. Plant breed. 15 (1): 103-116.

Glaz B. and Dean J.L. (1988). Statistical errors rates and their implications in sugarcane clone trials. Agron. J. 80: 560-562.

Kempton R.A., Seraphin J.C. and Sword A.M. (1994). Statistical analysis of two dimensional variation in variety yield trials. J. Agric. Sci. 122: 335-342.

Kirk H.J., Haynes F.L. and Monroe R.J. (1980). Application of trend analysis to horticultural field trials. J. Amer. Soc. Hort. Sci. 105 (2): 189-193.

Kirk R.E. (1995). Experimental Design: Procedures for the Behavioral Science ( $3^{\text {rd }}$ ed.), Pacific Grove, CA: Brooks/cole publishing.

Lin C.S., Binns M.R., Voldeg H.D. and Guillemett R. (1993). Performance of randomized block designs in field experiments. Agron. J. 85: 168-171.
Nasr S.M. (1994). Use trend analysis in statistical decision making in crop research. J. Agric. Sci., Mansoura Univ., 19(7): 2127-2138.

Nasr S.M. and El-Hady M.M. (1999). The use of trend analysis to remove spatial variation from field plot data. Bull. Fac. Agric., Cairo Univ. $50: 41-54$.

Pearce S.C. (1978). The control of environmental variation in some West Indian maize experiments. Trop. Agric. (Trinidad) 55: 97106.

Pearce S.C. (1980). Randomized blocks and some alternatives: a study in tropical conditions. Trop. Agric. (Trinidad) 57: 1-10.

Qiao C.G., Basford K.E., Delay I.H. and Cooper M. (2000). Evaluation of experimental designs and spatial analysis in wheat breeding trials. Theor. Appl. Genet. 100: 9-16.

Stroup W.W., Baenziger P.S. and Multize D.K. (1994). Removing spatial variation from wheat yield trials: a comparison of methods. Crop Sci. 86: 62-66.

Tamura R.N., Nelson L.A. and Naderman G.C. (1988). Investigation of the validity and usefulness of trend analysis for field plot data. Agron. J. 80: 712-718.

Warren J.A. and Mendez I. (1982). Methods for estimating background variation in field experiments. Agron. J. 74: 1004-1009.

$$
\begin{aligned}
& \text { استخدام نماذج تحليل الإتعاه لزيادة كفاءة تجارب الاصناف في القمح } \\
& \text { محمد أحمد هاجر } \\
& \text { قسم المحاصيل - كلية الزر اعة - جامعة الأز هر - القاهرة - مصر. }
\end{aligned}
$$

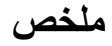

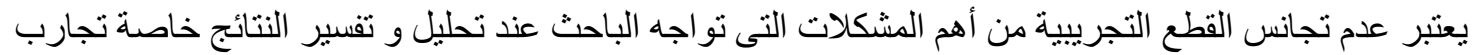

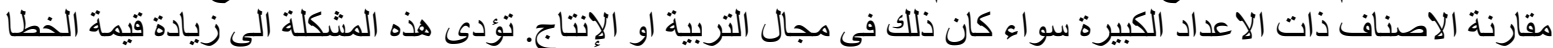

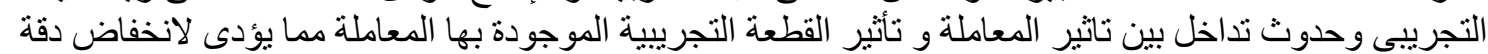

$$
\begin{aligned}
& \text { التحليل. } \\
& \text { وفى الحقيقة فان استخدام اسلوب القطاعات ( سو اء الكاملة او غير الكاملة ) فى التصميمات التقليدية قد لا يكون كافيا }
\end{aligned}
$$

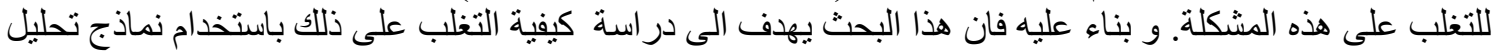

$$
\begin{aligned}
& \text { الاتجاه كاسلوب بديل لتحليل التباين الخاص بالتهان التصميمات التقليدية. }
\end{aligned}
$$

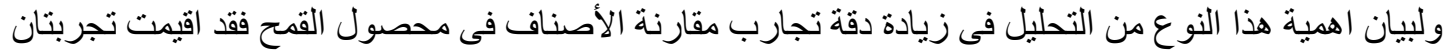

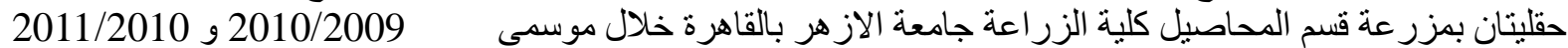

$$
\begin{aligned}
& \text { للمقارنة بين } 29 \text { نركيب ور اثى من القمح بالاضافة الى الصنف التجاري (جيزة التيزة }
\end{aligned}
$$

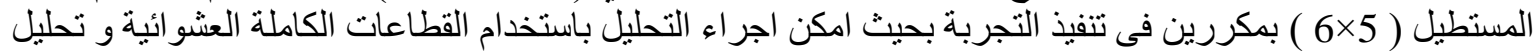

$$
\begin{aligned}
& \text { التصميم الثبكى المتبع بالإضافة إلى إستخدام نماذج تحليل التحليل الاتجاه. } \\
& \text { وقد تم تقييم ومقارنة طرق التحليل المختلفة باستخدام } 4 \text { مقاييس الحصائية كما يلى :- }
\end{aligned}
$$




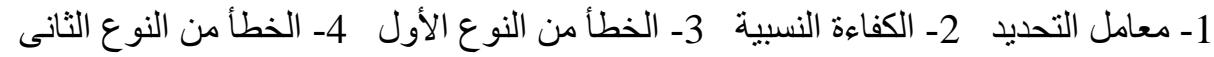

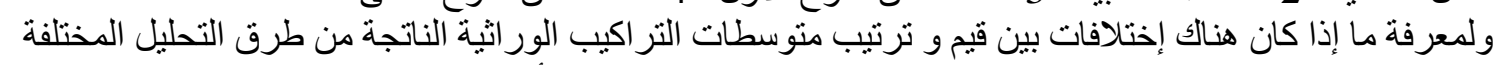

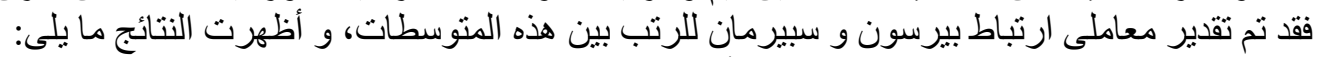

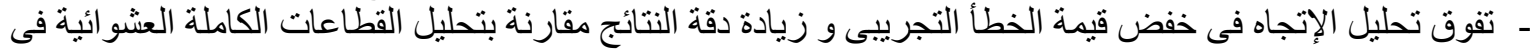

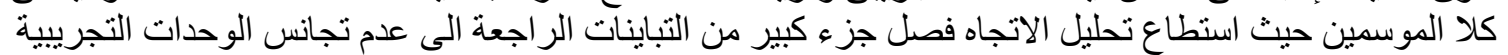

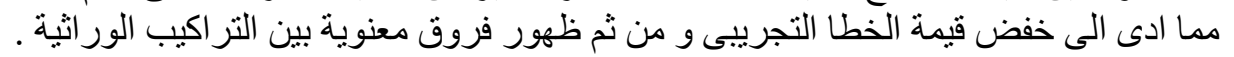

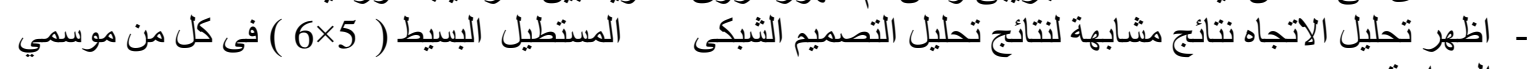

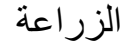

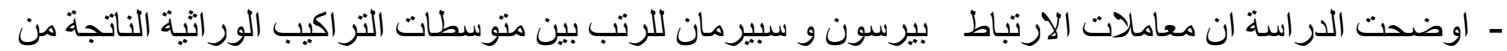

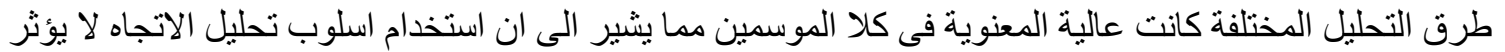

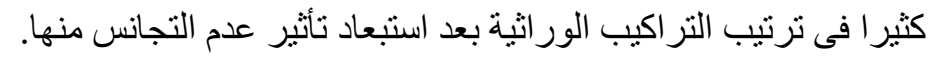

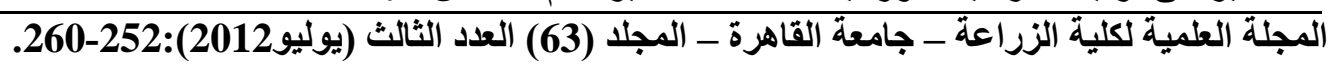


Table (5): Pearson (above diagonal) and Spearman (below diagonal) correlation coefficients between wheat genotype means for the used models of analysis during 2009/2010 and 2010/2011 seasons.

\begin{tabular}{|l|r|r|r||r|r|r|}
\hline \multirow{2}{*}{$\begin{array}{l}\text { Models of } \\
\text { analysis }\end{array}$} & \multicolumn{3}{|c||}{$\mathbf{2 0 0 9 / 2 0 1 0}$} & \multicolumn{2}{|c|}{$\mathbf{2 0 1 0 / 2 0 1 1}$} \\
\cline { 2 - 7 } & RCBD & Lattice & Trend & RCBD & Lattice & \multicolumn{1}{l|}{ Trend } \\
\hline Lattice & 1 & $0.89 * *$ & $0.99^{* *}$ & 1 & $0.88^{* *}$ & $0.90^{* *}$ \\
\hline Trend & $0.86^{* *}$ & 1 & $0.97 * *$ & $0.88^{* *}$ & 1 & $0.98^{* *}$ \\
\hline
\end{tabular}

**: Significant at 0.01 probability level of analysis. 